\title{
Uma discussão sobre documento audiovisual enquanto patrimônio arquivístico cultural no Brasil
}

Una discusión sobre el documento audiovisual como patrimonio archivístico cultural en Brasil

A discussion on audiovisual documents as cultural and archival heritage in Brazil

\author{
Luiz Antonio Santana da SILVA (1), Telma Campanha de Carvalho MADIo (2)
}

Universidade Estadual Paulista, Unesp, José Godoy Alves, 158, Cid Pimentel, CEP. 17560-000, Vera Cruz, SP, Brasil (1) santana_luiz06@yahoo.com.br (2) telmaccarvalho@marilia.unesp.br

\section{Resumen}

Se analiza el orígen del concepto de patrimonio y su definición y aplicabilidad en el escenário brasileño, centrándose especialmente los documentos audiovisuales como patrimonio archivístico.

Palabras clave: Documentos audiovisuales. Patrimonio cultural. Archivos.

\section{Origem do conceito de patrimônio: breve histórico}

A ideia de patrimônio nas sociedades modernas é oriunda da Europa, surgida em um momento radical —a Revolução Francesa de 1789- juntamente com a expansão das tropas napoleônicas. A princípio, tem-se o primeiro pensamento de patrimônio, com uma abrangência ainda restrita do conceito, proveniente da França. A política do Terror instaurada na França, desencadeada pelos jacobinos, resultou na destruição e ruínas de bens eclesiásticos e aristocráticos da monarquia absolutista francesa.

Essa ação de revolta contra os bens da monarquia pregava a liberdade e a igualdade, pois não permitiam expor aos franceses os monumentos construídos para alimentar o orgulho e a pompa da tirania. Por abaixo os monumentos franceses era a ordem dada a fim de eliminar qualquer resquício eclesiástico ou aristocrático. A Revolução, segundo Alves (2008), tomava um rumo diferente fugindo do controle, e a preocupação com os ideais revolucionários bem como com a própria Revolução era emergente. Tal preocupação é perceptível nas palavras do deputado Barnave em carta enviada ao Rei em 1791:

Vamos terminar a Revolução, vamos recomeçá-la? [...] Tornastes todos os homens iguais perante a lei, consagrastes a igualdade civil e política; retomastes para o Estado tudo o que tinha sido tirado à soberania do povo; um passo a mais seria um

\begin{abstract}
The origin of the concept of cultural heritage and its definition and applicability to the Brazilian scenery is analyzed, with a focus on audiovisual archives.
\end{abstract}

Keywords: Audiovisual documents. Cultural heritage. Archives.

ato funesto e culposo, um passo a mais na linha da liberdade seria a destruição da realeza; na linha da igualdade, a destruição da propriedade. (Bluche, Rials e Tulard, 1989, p. 72-73).

No entanto, o ponto importante exposto na fala do deputado francês é a questão da destruição da propriedade, além da preocupação com o desenrolar da Revolução. Sendo assim, a demolição dos monumentos na França é confirmada pelas palavras de Barnave. Em resposta à atitude radical difundida e desempenhada pelos jacobinos, constituintes da Assembleia Nacional, a República Francesa deu início a um processo de criação de novos símbolos nacionais. Tais símbolos que foram idealizados eran (Corrêa, 2008, p. 53):

Novas bandeiras, novo calendário, novos hinos, nova arquitetura, isto é, novos símbolos identitários nacionais. Esse período de transformações inaugurou um debate em torno do que deveria ou não se preservado do passado gótico, eclesiástico e monárquico francês e, por extensão, da comunidade europeia.

Começa-se, a partir desse processo de criação, a reformulação do conceito de patrimônio histórico, assim como o que deveria ser considerado ou não patrimônio nacional. Em continuidade à iniciativa da República Francesa, o estudo da Legislação aplicada aos monumentos históricos torna-se importante, pois se consolidou um modelo para toda Europa assim como para outros países, inclusive o Brasil num momento posterior. A partir do século $X X$, o conceito de patrimô- 
nio começa a ser difundido no Brasil, porém o conceito de patrimônio surgiu em meados do século XVIII. Contudo, há ainda forte resistência no alargamento do conceito de monumento histórico para então se definir o que seria ou não considerado patrimônio histórico.

Uma vez designado patrimônio histórico, os monumentos passariam a ser considerados locais detentores de memória. Além de locais de memória, a nova sociedade que surgia na França, por meio da reformulação sociopolítica e econômica, teria o direito de evocar um passado do qual fazia parte. Os monumentos históricos tidos como patrimônio, agora tinham como função propiciar um olhar para o passado, porém no presente.

A dificuldade de ampliar o conceito de monumento histórico é encontrada na França e Brasil respectivamente, uma vez que o Brasil importou o modelo francês de como lidar com monumentos ditos históricos. Corroborando esse aspecto inconsistente da abordagem conceitual de monumento histórico, Corrêa (2008, p. 55) diz o seguinte:

Por outro lado, da mesma forma que no Brasil, na sociedade francesa a definição de monumento histórico - móvel ou imóvel 'cuja conservação apresenta, do ponto de vista da história e da arte, um interesse público' —consolidou toda uma prática patrimonial. Porém, esta posição cristalizará uma visão fechada e conservadora que não será melhorada com a simples introdução de novos tipos de objetos no corpus dos monumentos. Todo o arcabouço conceptual sobre o qual se baseou essa definição restritiva não se sustenta com uma mínima análise da própria noção, pois a ideia de monumento histórico carece de uma efetiva concretude; já que apela para a petrificação do vivido.

Devido à inconsistência e à falta de enriquecimento conceitual do que venha a ser considerado monumento histórico, houve atraso em relação ao reconhecimento, tratamento e manutenção dos monumentos franceses. Somente no século XIX, mais precisamente em 1830, com a criação do Comitê de Trabalhos Técnicos Históricos (CTH) e da Comissão de Monumentos Históricos em 1837 (CMH), o trabalho de classificação e registro de monumentos históricos foi efetivamente desempenhado com competência.

Essa breve abordagem histórica mostra alguns pontos relevantes para o processo de constituição do instituto de proteção de monumentos históricos na França, que se reflete no Brasil, mais de cem anos após ter se originado na França. No Brasil, a política protecionista começou a partir da criação do Museu Histórico Nacional em 1922, com a finalidade de recolher, classificar e expor ao público objetos com im- portância histórica. Como dizia Mario de Andrade (1), é preciso abrasileirar os brasileiros. Não somente abrasileirar os brasileiros, mas também cobrar do poder público medidas protecionistas para objetos que auxiliem na constituição e revalorização da identidade nacional.

Com relação aos documentos audiovisuais como patrimônio, mais uma vez, a França destaca-se sendo considerado o berço onde nasce a ideia de patrimônio documental, como se conhece na atualidade. Além da questão que engloba a documentação como patrimônio de uma nação, a política francesa atual vai além, pois insere no rol de discussões sobre patrimônio documental, o audiovisual na sua mais pura essência, ou seja, o conceito em si de audiovisual também como patrimônio. Quanto à essência do audiovisual, isto é, qualquer obra, produção ou documento audiovisual é considerado patrimônio, mesmo não sendo documento arquivístico. Assim, qualquer documento no gênero audiovisual é patrimônio de uma nação se esse representar algum valor histórico e cultural.

Com a finalidade de explicitar claramente tal abordagem da documentação e do audiovisual como patrimônios, visão concebida na política francesa de patrimônio documental, Corrêa (2008, p. 56) aponta detalhadamente como a política se desdobra até atingir o audiovisual como patrimônio:

No Ministério da Cultura e da Francofonia existe uma Direção do Patrimônio, como um Conselho do Patrimônio Etnológico. Esse Conselho é constituído pelos departamentos Setoriais de Etnologia vinculados as Direções Regionais de Assuntos Culturais (DRAC). As ações da Missão do Patrimônio Etnológico francês dividem-se nos seguintes domínios: pesquisa, formação, publicação, audiovisual, documentação, ação cultural e intercâmbios internacionais.

Sendo assim, chegou-se ao ponto importante para dar continuidade à discussão sobre o caráter patrimonial dos documentos audiovisuais no Brasil. Partindo dessa base, oferecida pela política francesa, pode-se discutir o documento de arquivo registrado em suporte fílmico, como patrimônio documental arquivístico de uma nação, estado, município ou grupos de pessoas físicas e/ou jurídicas que guardam informações de interesse público neles contidos.

Além disso, registram fatos que evocam a memória nacional, institucional, dependendo do contexto no qual tais documentos são provenientes. No Brasil, somente na segunda metade do século $X X$, os documentos passam a ser considerados patrimônios. 


\section{O que é patrimônio?}

O conceito de patrimônio possui uma abrangência que vai da definição mais geral à mais específica, ou seja, possui significado multinível. Pretende-se, aqui, discorrer sobre algumas definições de patrimônio, bem como quais elementos venham a ser dignos de receber o status de patrimônio. O significado da palavra tem origem latina, no qual "patrimonium" significava, entre os antigos romanos, tudo o que pertencia ao pai, pater ou pater familias, pais de família inclusive a mulher, os filhos e os escravos, os animais e os bens móveis e imóveis." (Castro, 2008, p. 11).

A primeira definição encontrada foi extraída do dicionário de Língua Portuguesa, no qual se visualizou a origem da palavra subdividindo-se em cinco definições. Desse modo, a definição diz: 1 Herança paterna. 2 Bens de família. 3 Bens necessários à ordenação e sustentação de um eclesiástico. 4 Quaisquer bens materiais ou morais, pertencentes a uma pessoa, instituição ou coletividade. 5 Reg (São Paulo) Povoação. P. nacional: departamento administrativo subordinado ao Ministério da Fazenda e onde se encontram cadastrados todos os bens do domínio da União ou próprios nacionais: bens imóveis, material bélico, terrenos e acrescidos de marinha e outros.

Nessa definição é possível notar que há amplitude do significado, assim como há desconsideração de bens imateriais (paisagens, danças, etc.). Também descarta qualquer possibilidade de acervos documentais serem considerados como patrimônio. $O$ resultado não poderia ser tão diferente, já que se trata de um dicionário para simples compreensão de qualquer palavra da língua portuguesa. Caminhando rumo aos acervos como patrimônios, têm-se os enunciados do Dicionário Brasileiro de Terminologia Arquivística, publicado pelo Arquivo Nacional (2005, p 130), que desmembra o termo patrimônio em duas definições:

Patrimônio arquivístico: conjunto dos arquivos de valor permanente, públicos ou privados, existentes no âmbito de uma nação, de um estado ou de um município. [...] O Patrimônio arquivístico comum: arquivo que constitui o patrimônio arquivístico de duas ou mais unidades territoriais, não podendo ser dividido sob pena de perda de sua integridade.

Qualquer documento de arquivo, textual ou não, de valor permanente ou histórico, é considerado patrimônio arquivístico, porque é pertencente a um determinado grupo concebendo sua memória. Já a segunda definição está muito mais ligada com alguns princípios básicos da arqui- vística, não permitindo a divisão em partes, pois se destituem da inteireza que os torna comum.

As definições do Dicionário Brasileiro de Terminologia Arquivística dão inicio à questão primordial para o desenvolvimento do enfoque dos documentos de cunho arquivístico como patrimônio. Sendo assim, pode-se inferir que patrimônio arquivístico é todo e qualquer documento de arquivo pertencente a uma pessoa física ou jurídica registrado em qualquer suporte. A terceira, e última, definição se apresenta de forma imponente e demarcadora, pois toca o documento audiovisual com propriedade dando a ele o status de patrimônio documental e também cultural.

Dessa forma, nessa última definição de patrimônio proposta por Lopes, Macedo e Machado (2010 p. 7-13) começa-se o aprofundamento do significado e dos elementos designados bens patrimoniais. Dá-se inicio também, ao desmembramento em outras pequenas definições, sendo que a última dessas é mais apropriada para essa discussão porque diz claramente que não só documentos tradicionais, mas também documentos fílmicos, imagéticos e fotográficos são assinalados como patrimônio documental.

Patrimônio: são os bens pertencentes a uma pessoa, a uma família ou a uma comunidade. Patrimônio é sinônimo de riqueza desde que entendida como expressão de uma tradição, de uma identidade cultural, das crenças e valores cultivados coletivamente.

Definição geral, porém demarca aparentemente os bens de uma pessoa ou povoado como patrimônios oriundos de seus contextos. Mais uma vez, o bem tido como patrimônio tem o poder de evocar memórias coletivas que, por conseguinte, servem de subsidio para a construção de identidades. Quanto à construção de identidade, a próxima definição aprofunda esse ponto (ibidem):

Patrimônio Cultural: diz respeito à identidade cultural de um povo e da humanidade. Ele é o conjunto de todas as expressões e manifestações culturais. Nesse sentido, as peças de acervos em museus, documentos guardados em arquivos, bens antigos, casas, prédios, monumentos, objetos, hábitos alimentares, vestimentas, modos de vida, fazeres e saberes manuais, artesanais, crenças, dentre outras tradições, constituem e constroem nossa identidade cultural.

Cabe aqui salientar que todos os documentos guardados em arquivos, públicos ou privados, além de serem considerados patrimônios documentais, também são patrimônios culturais, pois dizem respeito à determinada cultura, que refletem a identidade cultural de um povo carecendo de atenção do poder público quanto a sua corre- 
ta preservação e difusão. Todo individuo tem o direito de estar informado sobre sua identidade cultural, assim como ser amparado pelas políticas públicas de proteção, preservação e disseminação desse conhecimento cultural (ibidem):

Patrimônio documental: pode ser escrito, sonoro, audiovisual, eletrônico, digital ou imagético. Registra um tempo, uma época. Os escritos são geralmente confeccionados em papéis, como certidões, livros, cartas e guardam parte da memória de uma pessoa ou de uma comunidade. Os imagéticos são aqueles que revelam por meio de fotografias, filmes, folders, obras de arte a história de um lugar, de uma família, de um país, de uma festa, de comemorações ou mesmo de eventos marcantes para uma sociedade.

Aliados, patrimônios documentais e culturais representam a identidade de uma nação e, portanto, devem ser preservados para que a sociedade conheça mais de si mesma, sendo esse um direito de todo cidadão. Porém há grande distanciamento entre questões teórico-práticas no que tange ao direito cultural no Brasil. Como mostra Fonseca (1997), somente na constituição brasileira de 1988 (art. 215) surge a expressão "direitos culturais", no entanto tal temática ainda não foi imbuída nas políticas públicas de fato.

Portanto, entende-se patrimônio como todos os bens materiais, imateriais pertencentes a uma determinada pessoa, comunidade, município, estado ou nação que represente suas ações durante o decorrer das relações sociais. $\mathrm{O}$ patrimônio de uma nação seja documental, cultural, material ou imaterial representa a memória dos indivíduos que estiveram envolvidos no processo de formação da nação subsidiando a memória coletiva com vistas à construção da memória nacional.

\section{O documento audiovisual como patrimônio arquivístico}

Antes de se discutir o documento audiovisual como patrimônio arquivístico, é preciso ressaltar alguns fatos importantes para que tais documentos, textuais ou não, passassem a ser considerados como tal no Brasil. Esse processo de reconhecimento teve origem em um período turbulento para o país. Sendo assim, sob o regime da ditadura na década de 1930, tem-se o primeiro passo para a proteção do patrimônio nacional. No Brasil no ano de 1937, o então presidente Getúlio Vargas assina o Decreto Lei $\mathrm{n}^{\circ} 25$, que dispõe sobre a organização do patrimônio histórico e artístico nacional. (Camargo e Molina, 2010).
Um fato curioso, e até mesmo contrastante, é a questão da preocupação com a preservação da memória nacional surgir em meio a um governo ditatorial. Com o desencadeamento de Decretos-Lei e atos legais a partir de 1937 para a preservação patrimonial, sendo considerados patrimônios os acervos pessoais da época, houve um avanço gradativo que se estendeu até os dias de hoje.

Somente na década de 1990 se tem uma lei que dispõe sobre a política nacional de arquivos públicos e privados. Como mostram Camargo e Molina (2010), a Lei $n^{\circ} 8.159$ de janeiro de 1991 que dispõe sobre a política nacional de arquivos públicos e privados e dá outras providências, institucionaliza tais arquivos como integrantes da identidade nacional brasileira.

Diferentemente de outros países, nesse caso, traçando um paralelo com a França, o Brasil demonstra atrasos quanto à consciência e vontade do poder público de preservação do seu patrimônio documental. Reafirmando esse fato, Camargo (1999, p. 56) destaca que "em países como o Brasil, o trato do registro documental e da informação ainda difere bastante daquele existente nos países ditos 'avançados'”.

Posteriormente a essa Lei, muitos arquivos, em especial os privados, vêm sendo declarados de interesse público para a constituição e manutenção da memória nacional. Pode-se concluir que esses arquivos são patrimônios arquivísticos nacionais, pois têm o poder de registrar fatos relevantes para a memória nacional, cumprindo o valor histórico do documento arquivístico. Outro dado importante desses acervos é a composição variada de seus materiais e documentos, possuindo vários tipos, formatos e suportes documentais. Destaca-se que são considerados os documentos destituídos de caracteres, isto é, documentos imagéticos, fotográficos e audiovisuais como patrimônios documentais.

Um bom exemplo de arquivo pessoal declarado como sendo de interesse público, é o arquivo privado do cineasta brasileiro Glauber Rocha, pois se compõe de livros, desenhos, roteiros, cartas, cartazes e cópias em vídeo dos filmes que estão empilhados e dispostos em armários e estantes improvisadas. O Parecer $\mathrm{N}^{\circ} 06 / 2005$ manifesta-se sobre a declaração de interesse público e social do acervo do cineasta Glauber Rocha, sob a guarda do "Tempo Glauber". Acervo riquíssimo para a memória nacional, porém os originais dos filmes estão preservados na Cinemateca Brasileira.

A Cinemateca Brasileira surgiu a partir da criação do Clube de Cinema de São Paulo, em 1940. Seus fundadores eram jovens estudantes 
do curso de Filosofia da USP, entre eles, Paulo Emílio Salles Gomes, Décio de Almeida Prado e Antonio Candido de Mello e Souza. O Clube foi fechado pela polícia do Estado Novo. Após várias tentativas de se organizarem cineclubes, foi inaugurado, em 1946, o segundo Clube de Cinema de São Paulo. Seu acervo de filmes constituiu a Filmoteca do Museu de Arte Moderna (MAM), que viria a se tornar uma das primeiras instituições de arquivos de filmes a se filiar à FIAF - Fédération Internationale des Archives du Film, em 1948. Em 1984, a Cinemateca foi incorporada ao governo federal como um órgão do então Ministério de Educação e Cultura (MEC) e hoje está ligada à Secretaria do Audiovisual.

A Cinemateca Brasileira é a instituição localizada em São Paulo, responsável pela preservação da produção audiovisual brasileira. Desenvolve atividades em torno da difusão e da restauração de seu acervo, um dos maiores da América Latina. São cerca de 200 mil rolos de filmes, entre longas, curtas e cine jornais. Possui também um amplo acervo de documentos formado por livros, revistas, roteiros originais, fotografias e cartazes. Os documentos originais são restaurados, higienizados e acondicionados em material de longa permanência e depositados em uma reserva técnica climatizada.

Após a explanação da ideia de patrimônio arquivístico, abordar o documento audiovisual enquanto patrimônio se faz necessário para sedimentar teoricamente a discussão, tecendo relações entre o audiovisual, a arquivística e o patrimônio. Embasar questões que envolvam o documento audiovisual é indispensável, uma vez que não existe unanimidade em relação a esse gênero documental quando tratado no âmbito arquivístico. Sendo assim, destacar e delinear como o audiovisual é visto pela arquivística no país é de extrema relevância.

Definir e compreender o que é documentação audiovisual para esclarecer qual o perfil desse gênero documental nos arquivos é relevante. Para isso, foi consultado o Dicionário Brasileiro de Terminologia Arquivística (2005, p. 73) que classifica documentação audiovisual na seguinte conformidade:

gênero documental integrado por documentos que contêm imagens, fixas ou em movimento, e registros sonoros, como filmes e fitas videomagnéticas.

Já a definição encontrada no dicionário de Heloísa Liberalli Bellotto e Ana Maria de Almeida Camargo, é: "Gênero documental que utiliza como linguagem básica à associação do som e da imagem". (Dicionário de Terminologia Arquivística, 1996, p. 27).
Definição bem concisa em relação à anterior porque estabelece que documento audiovisual é um documento que contenha imagem e som.

Partindo para outra definição as autoras Cirne e Ferreira (2002, p. 116) buscam uma definição de documento audiovisual embasadas nos dicionários de terminologia arquivística de Lisboa publicado em 1993. Mesmo a arquivística brasileira possuindo raízes ibéricas, apresenta diferenças no conceito de documento audiovisual frente ao português. Assim sendo, a definição portuguesa é:

Assim, e segundo um conceituado instrumento de apoio da moderna arquivística, um documento audiovisual é um documento cuja informação é veiculada através de um código de imagens fixas ou móveis, e de sons, carecendo de equipamentos apropriados para ser visto e ouvido.

Nesse levantamento foi possível perceber que não há um consenso na definição do que é documento audiovisual. $\mathrm{Na}$ primeira definição, documento audiovisual pode ser considerado qualquer documento que possua imagem, seja ela fixa ou móvel. Já na segunda, há uma mudança, pois um documento audiovisual é constituído pela associação de som e imagens apenas. E na terceira, é uma junção das definições anteriores, o que faz com que o conceito de audiovisual ainda não possua um consenso.

A definição mais apropriada e coerente de acordo com a origem etimológica da palavra (audiovisual: relativo ou pertencente simultaneamente à audição e visão) é a que define o audiovisual como associação básica de som e imagem registrados em suporte fílmico. Além dessas características arquivísticas atribuídas aos documentos audiovisuais, dando-Ihes caráter probatório e posteriormente guardador de memória, outra faceta do documento audiovisual se mostra: a patrimonial.

Somado ao status de patrimônio, o audiovisual também é munido de valor cultural, pois registra e guarda partes das ações humanas de um determinado período da vida que, em longo prazo, servirão para constituição de memória. Em relação ao aspecto probatório, cultural e detentor de memória Heymann (2009) delineia muito bem o movimento pelo qual passa os arquivos.

Vistos como os meios de acesso seguro ao passa-
do, os arquivos funcionam como "prova" das traje-
tórias as quais se busca associar o atributo da
exemplaridade e da singularidade, fundamentais a
construção da noção de "legado". Nesse movimen-
to, os acervos são associados a categoria de pa-
trimônio, e passam a ser vistos como materiais cu-
ja preservação deve ser garantida em nome da 
memória da coletividade, seja local seja nacional. (p. 01).

Através desse viés patrimonial abordando os arquivos, torna-se indispensável promover um diálogo abarcando o documento audiovisual como patrimônio, pois esse tem o papel de detentor e perpetuador de memória. Assim Edmondson (1998, p. 5), em uma definição mais abrangente de patrimônio audiovisual, pontua os filmes como constituintes desse patrimônio, fazendo a seguinte afirmação:

o patrimônio audiovisual inclui filmes produzidos, distribuídos, transmitidos (radiodifundidos) ou noutros casos tornados disponíveis ao público, com ou sem som que quando projetados dá uma impressão de movimento.

Os documentos audiovisuais definidos acima podem ser compreendidos como o núcleo de uma gama maior de material e informação reunida pelas instituições de arquivo, sendo considerada como patrimônio audiovisual. Como dito anteriormente, o audiovisual é um tema trabaIhoso de ser discutido porque existe controvérsia entre os teóricos da área. Alguns teóricos chamam essa gama maior de documentação de apoio, ou seja, toda documentação textual, têxtil, iconográfica que tem relação com o documento audiovisual é considerado documento de apoio, desvinculando do caráter de patrimônio audiovisual. Tem-se então a proposta de patrimônio audiovisual definida assim por Edmondson (1998, p. 7):

a) Som gravado, rádio, filme, televisão, vídeo ou outras produções que incluem imagens em movimento e/ou registros sonoros, quer tenham sido ou não intencionalmente concebidos para divulgação pública.

b) Objetos, documentos, trabalhos e elementos intangíveis relacionados com os documentos audiovisuais, que vistas de um ponto de vista técnico, industrial, cultural, histórico ou outro; isto incluirá material relativo ao filme, radiodifusão e indústrias de gravação, como literatura, guiãos, fotografias, cartazes, materiais publicitários, manuscritos e artefatos como equipamento técnico ou roupas.

Segundo essa definição, o patrimônio audiovisual é composto também por materiais textuais como os scripts, que se relacionam com os documentos audiovisuais, assim como outros tipos de materiais diferentes dos encontrados em acervos audiovisuais. A partir desse conceito de patrimônio, tomando, por exemplo, uma produtora, toda documentação produzida para um filme cinematográfico, desde o momento de criação do filme pelo autor, roteiro até a divulgação, formam o patrimônio audiovisual. Portanto, o documento audiovisual é patrimônio documen- tal de instituição pública ou privada, tendo como função final garantir a memória.

Reforçando o fato dos documentos serem reconhecidos como patrimônio documental, inclusive no Brasil, tem-se em âmbito nacional o Comitê Nacional do Brasil do Programa Memória do Mundo da UNESCO criado em 2004, regulamento pela portaria do Ministério da Cultura. No geral, o comitê visa a assegurar a preservação e o acesso ao patrimônio documental e bibliográfico de importância mundial. Em síntese, segundo Heymann (2009), a composição do comitê se dá basicamente pela nomeação de 15 membros, representantes de seis instituições, sendo elas: Arquivo Nacional, Conselho Nacional de Arquivos, Comissão Nacional da UNES$\mathrm{CO}$, Biblioteca Nacional, IPHAN e Ministério da Cultura.

Ainda há sete seguimentos que compõem o comitê. São eles os arquivos: audiovisuais, eclesiásticos, militares, municipais, estaduais, privados seguidos das associações de ensino e pesquisa. Por conseguinte, o documento audiovisual é patrimônio documental, e como tal, deve receber todos os meios legais para sua correta preservação.

Recentemente, outro órgão responsável pela produção audiovisual brasileira foi criado, a fim de salvaguardar o patrimônio audiovisual brasileiro: a Secretaria do Audiovisual. Como missão, a SAv busca

fazer frente aos desafios do novo cenário Brasileiro, a Secretaria do Audiovisual do Ministério da Cultura trabalha no sentido de promover medidas institucionais para estimular o reconhecimento da criatividade e da diversidade cultural, traduzida na produção audiovisual brasileira; a inclusão digital; a democratização e a regionalização do acesso a conteúdos audiovisuais brasileiros; a o fortalecimento da capacitação e formação em todos os níveis do setor audiovisual; a adequação da estrutura institucional; viabilizar o desenvolvimento sustentável do setor audiovisual; e garantir a legitimidade na elaboração de políticas estratégicas, de estruturação, desburocratização e inovação audiovisual.

A Secretaria do Audiovisual (SAv) é órgão específico e singular da estrutura organizacional do Ministério da Cultura (MinC). Suas competências estão definidas no Decreto $N^{\circ} 7.743$, de 31 de maio de 2012. Destacamos o parágrafo terceiro desse decreto:

III - formular políticas, diretrizes e metas para formação e capacitação audiovisual, produção, distribuição, exibição, preservação e difusão de conteúdos audiovisuais e cinematográficos brasileiros, respeitadas as diretrizes da política nacional do ci- 
nema e do audiovisual e do Plano Nacional de Cultura;

Assim, a SAv trabalha empregando políticas que garantam a produção audiovisual brasileira enquanto patrimônio cultural do Brasil.

\section{Considerações finais}

O objetivo principal que conduziu a discussão nesse trabalho foi estabelecer e apresentar a relação intrínseca entre o documento audiovisual de caráter arquivístico com o conceito de patrimônio apontando alguns fatos ocorridos no cenário nacional envolvendo essa temática. Além disso, definir e embasar teoricamente o documento audiovisual como patrimônio arquivístico também foi um dos pontos principais nessa abordagem. Visou-se a localizar a origem do conceito de patrimônio, historicamente, a fim de pautar algumas questões que definiram o conceito de patrimônio, tanto quanto sua aplicabilidade.

Outro ponto discutido foi a configuração que assume um documento audiovisual em ambiente de arquivo sob o olhar da arquivística. $O$ documento audiovisual possui vários conceitos, e assim sendo, oferece uma gama de discussões entre vários teóricos que abordam esses documentos. Procurou-se situar o documento audiovisual em meio à diversidade de conceitos assim como as discrepâncias inerentes ao tema proposto para discussão.

Um aspecto peculiar que pode ser percebido é a diversidade de conceitos de Patrimônio e documento audiovisual, sendo esse último diverso e controverso ao passo que os conceitos de patrimônio se completam, pois abrangem os elementos designados patrimônios desde o mais simples objeto ao intangível. O perfil cultural do patrimônio é questão irrevogável, uma vez que o patrimônio tem por função resguardar memória que é constituída por uma nação, refletindo sua própria cultura.

Partindo desse embasamento, pode-se definir o perfil patrimonial que assume os documentos audiovisuais munidos de valor secundário ou histórico, servindo como subsídio para a construção da memória nacional, tanto quanto registrando manifestações culturais que definem a identidade de uma sociedade. Desse modo, preservar o patrimônio é preservar a nação. Se o patrimônio é ameaçado, a própria existência da nação como uma identidade presente é questionada. Assim sendo, ele é um lugar de memória que permite compor imagens que alicerçam identidades individuais e coletivas.

\section{Notas}

(1) Importante escritor modernista brasileiro, que atuou como diretor do Departamento de Cultura do Estado de São Paulo na década de 1930. Na mesma década, cria a Sociedade de Etnologia e Folclore de São Paulo, sendo seu primeiro presidente. Organiza o $1^{\circ}$. Congresso da Língua Nacional Cantada. Também é responsável por projetar a criação do Serviço do Patrimônio Histórico e Artístico Nacional, SPHAN. É nomeado encarregado do Setor de São Paulo e Mato Grosso.

\section{Referências}

Alves, M. (2008). Da virtude ao terror. // Princípios. Natal. 15:23 (jan/dez) 89-116.

Arquivo Nacional (Brasil) (2005). Dicionário Brasileiro de Terminologia Arquivística. Rio de Janeiro: Arquivo Nacional.

Belloto, H. L; Camargo, A. M. (1996). Dicionário de terminologia arquivística. São Paulo: AAB, 1996.

Bluche, F; Rials, S.; T, J. A. (1989). Revolução Francesa. Trad. Lucy Magalhães. Rio de Janeiro: Jorge Zahar,.

Camargo, C. R.; Molina, T. S. (2012). O Patrimônio Arquivístico: acervos privados e interesse público. // XIV encontro regional da ANPUH-rio memória e patrimônio, 2010. Anais. Rio de Janeiro: Rio de Janeiro.

Castro, C (2008). Pesquisando em Arquivos. Rio de Janeiro: Jorge Zahar.

Cirne, M. T.; Ferreira, S. M. (2002). A ética para os profissionais da informação audiovisual: o devir tecnológico amoldar uma atitude. // Cadernos de Biblioteconomia Arquivistica e Documentação: Revista da APBAD. Lisboa. 1.115-129.

Corrêa, A. F. (2008). Patrimônios Bioculturais: ensaios de antropologia do patrimônio cultural e das memórias sociais. São Luís: Edufma.

Edmondson, R. (1998). Uma filosofia dos arquivos audiovisuais. Paris: UNESCO.

Fonseca, M. C. L. (1997). O Patrimônio em Processo: trajetória da política federal de preservação no Brasil. Rio de Janeiro; UFRJ: IPHAN.

Heymann, L. Q. (2009). Estratégias e Institucionalização de Patrimônios Históricos e Culturais: o lugar dos documentos. // VIII reunião de antropologia do MERCOSUL, 2009. Anais. Buenos Aires.

Lopes, V. M. Q. C.; Macedo, A. P. R.; Machado, M. C. T. (2010). Patrimônio Cultural. Que bicho é esse? Uberlândia: Secretaria Municipal de Cultura/Diretoria de Memória e Patrimônio Histórico. 50 p.

Ministério da cultura. Cinemateca brasileira. http://www.cine mateca.gov.br/page.php?id=1 (20 de Jul 2012).

Ministério da cultura. Secretaria do audiovisual. http:// www.cultura.gov.br/audiovisual/secretaria/sobre/ (20 de Jul 2012).

Silva, Z. L. (1999). Arquivos, Patrimônio e Memória. Trajetórias e Perspectivas. São Paulo: UNESP, 1999.

Enviado: 2012-04-18. Versión corregida: 2012-08-21. Aceptado: 2012-08-21. 



\section{Procedimiento de evaluación}

Evaluation process

\section{Introducción}

El procedimiento de evaluación en Ibersid es el de revisión por pares mediante el sistema de doble ciego - los revisores no conocen el nombre de los autores, ni viceversa- semejante al de otras revistas científicas, aunque tiene algunas peculiaridades que permiten ajustarlo a las condiciones específicas de su campo científico y de sus lectores.

\section{Objetivos}

El objetivo del procedimiento de evaluación es que se puedan admitir con rapidez los trabajos buenos, mejorar los que pueden ser susceptibles de aceptación —esto es, que, siendo interesantes, contienen errores o lagunas que deben ser corregidas - y rechazar los que no son adecuados para la revista por su tema o calidad, redirigiéndolos hacia otras publicaciones adecuadas o haciendo sugerencias al autor para la posible reutilización y reorientación de su trabajo.

El procedimiento de revisión tiene que tener en cuenta a los autores de los artículos que revisa, con los que el revisor debe intentar ser justo, pero también debe responder ante los lectores y los demás autores que compiten por el espacio de la revista, así como, de forma más general, con el proyecto editorial, la propia comunidad científica y el conjunto de la sociedad.

\section{Procedimiento}

Cada artículo requiere al menos la opinión favorable de al menos dos revisores y cada nota breve de al menos uno. Si el director de la revista estima que el artículo entra dentro de los objetivos de Ibersid —que se encuentran públicamente disponibles en cada número y en la página web de la revista-, lo envía a dos revisores - 0 , si es necesario, a más- elegidos por el director. Los evaluadores pueden ser miembros del consejo científico, revisores propuestos por los miembros del consejo científico con anterioridad o con motivo del artículo en cuestión, o científicos de reconocido prestigio propuestos por el autor o autores del artículo. La elección se hace según su conocimiento del tema y el número de trabajos que han evaluado hasta el momento (para equilibrar la carga de trabajo entre ellos).
Si el director estima sin lugar a dudas que el tema del artículo no se adecua al de la revista, se lo comunica al autor con una explicación suficiente, $y$, si le es posible, le sugiere otra revista que pueda ser más adecuada. De esta forma, se ahorra tiempo del autor y de los revisores.

La agilidad del procedimiento de revisión es un aspecto fundamental, por lo que el director solicita a los revisores que envíen su valoración en dos semanas, y que, en caso contrario, renuncien expresamente al proceso de revisión. Sin embargo, si el revisor no realiza ninguna de estas acciones, el proceso se retrasa sin remedio. En este sentido, el autor debe tener en cuenta que el proceso de revisión tiene un carácter voluntario. La decisión de aceptar el trabajo depende, salvo en casos excepcionales, de la opinión de los revisores. En los casos en que no están de acuerdo, la decisión es tomada por el director de la revista, que, excepcionalmente, puede decidir enviar el artículo a un nuevo revisor.

\section{Criterios de evaluación}

Se solicita a cada revisor que indique su valoración sobre los siguientes aspectos en una escala del 1 al 5 ( 1 muy cuestionable, 2 marginal, 3 suficiente, 4 sólido, 5 excelente):

1. Tipo de contribución: Se indica si se trata de una contribución de tipo teórico o metodológico, un estado de la cuestión, una comunicación de resultados de investigación, una experiencia específica, una exposición con valor introductorio o docente sobre el tema o una noticia de interés. Si es una mezcla de varios tipos, es posible marcar más de uno.

2. Adecuación del tema de la revista: Aunque al enviar el artículo al revisor el director de la revista ya ha realizado un juicio sobre su adecuación al enfoque de la revisa lbersid, el revisor puede también valorar este aspecto, comparando el tema del artículo con la declaración de objetivos y alcance de la revista, disponible en cada número y en la página web.

3. Interés e importancia del tema: Grado en el que el artículo aborda una cuestión de gran interés para el área científica de Ibersid, ya sea tradicionalmente, en el momento actual o en el futuro previsible. 
4. Actualidad del tema: Grado en el que el tema se sitúa en los frentes actuales de investigación. No es un aspecto imprescindible, pero sí se considera informativo.

5. Novedad y originalidad teórica de la aportación: Grado en el que el artículo aporta una novedad teórica a su campo de investigación; esto es, un nuevo problema, un nuevo enfoque, un nuevo modelo, una nueva relación o ley, una nueva hipótesis, un nuevo concepto o una interpretación o modificación original de otros anteriores. Debe tratarse lógicamente de una aportación relevante y fundamentada.

5. Novedad y originalidad metodológica de la aportación: Grado en el que el artículo aporta una novedad metodológica a su campo de investigación; esto es, un nuevo procedimiento de estudio, de análisis o de prueba, aunque sea a un problema conocido.

7. Aplicabilidad práctica: Grado en el que las ideas del artículo pueden servir para la mejora de procedimientos y actividades prácticas y, en definitiva, para el desarrollo y la innovación.

8. Rigor metodológico y validez de los resultados: Grado de coherencia, exactitud, precisión y cuidado con el que se aborda el tema de estudio; validez y actualidad de la metodología utilizada; rigor en la selección de las muestras y en la aplicación de la metodología a las mismas; grado de replicabilidad del estudio.

9. Rigor en el estado de la cuestión y el reconocimiento del trabajo previo: Hasta qué punto se ha realizado un estado de la cuestión suficiente $y$ actualizado y se han manejado las referencias pertinentes para el problema abordado.

10. Claridad expresiva, orden y facilidad de lectura: El artículo debe estar redactado de forma clara y bien ordenada, sin redundancias ni ideas fuera de contexto; y debe ser fácilmente entendible por cualquier lector potencial de Ibersid. No debe faltar información necesaria ni deben existir lagunas sobre el problema abordado, el método, los resultados, la discusión, las conclusiones o las recomendaciones. Si el artículo contiene aparato matemático, debe ser comprensible por un lector no especialista.

11. Adecuación de gráficos, ilustraciones, tablas $y$ apéndices: Los gráficos, ilustraciones, tablas y apéndices deben ser necesarios y relevantes, estar bien resueltos técnicamente y disponer de una leyenda suficientemente explicativa.

12. Conformidad de las referencias a las normas de la revista: Grado en el cuál las referencias del artículo son suficientes y se conforman a las normas de la revista Ibersid.

\section{Familiaridad del revisor con el tema}

Aunque el director de la revista envía los artículos para su revisión intentando que coincidan con el campo de especialidad del revisor, pueden producirse desajustes. El revisor puede rechazar la revisión sugiriendo o no un revisor alternativo, o puede efectuar la revisión indicando de 1 (mínimo) a 5 (máximo) su grado de familiaridad con el tema del artículo evaluado. Si no rellena esta información, se entenderá que su grado de familiaridad es alto (4) o muy alto (5).

Esta información sirve para que el director de la revista pueda estimar la necesidad de enviar el artículo a un nuevo revisor en caso de conflicto de pareceres entre los revisores.

\section{Valoración final}

El revisor puede realizar cinco tipos de propuestas finales:

1. Aceptar el artículo para su publicación sin restricciones ni cambios, porque es un trabajo de alta calidad.

2. Aceptar el artículo para su publicación una vez realizadas las correcciones indicadas, bien sea incondicionalmente, pues es un trabajo de calidad, o bien de forma condicionada a que haya espacio disponible en el número, por ser un trabajo de calidad marginal. Las correcciones solicitadas se indican en las instrucciones para el autor, son de carácter menor y su comprobación puede ser delegada en el comité editorial.

3. Someter a reevaluacion el artículo una vez realizadas las correcciones indicadas en las instrucciones para el autor, porque son de importancia y amplitud, y deben ser comprobadas por el revisor original u otro revisor.

4. Rechazar el artículo por las razones indicadas en las instrucciones para el autor, donde el revisor especificará con claridad y amabilidad las razones por las que su trabajo debe ser rechazado y, si le resulta posible, realizará sugerencias sobre su mejora o lugares alternativos de publicación.

5. El revisor rechaza evaluar el artículo por su falta de familiaridad con el tema o por razones que especifica en los Comentarios confidenciales para el equipo directivo.

La labor de los revisores es fundamental para que una publicación científica realice su labor de manera adecuada. Ibersid agradece de forma muy especial el tiempo y esfuerzo que dedican, y reconoce su trabajo publicando periódicamente sus nombres. 


\title{
Instrucciones para la presentación de trabajos
}

\author{
Instructions for authors
}

\section{Cuestiones generales}

Ibersid admite artículos con estados de la cuestión, discusiones de carácter teórico y metodológico, e informes de investigación sobre proyectos terminados, así como noticias sobre proyectos en curso, experiencias, notas y reseñas, que traten de la representación, normalización, tratamiento, recuperación y comunicación de la información y el conocimiento.

Las lenguas de publicación de Ibersid son el español, el inglés y el portugués.

Los artículos son sometidos a proceso de revisión por pares según el sistema de doble ciego, aunque los autores pueden proponer revisores libremente. El procedimiento es público, y puede ser leído en el apartado anterior a las instrucciones.

Los autores se comprometen a presentar y discutir públicamente y presencialmente sus trabajos en el congreso Ibersid correspondiente al año en curso.

Los trabajos deben ser originales y tendrán una extensión máxima de 20.000 caracteres en el caso de los artículos y de 12.000 caracteres en el caso de las noticias, experiencias, notas y reseñas. Excepcionalmente, estas cifras podrán ajustarse en virtud del interés del trabajo, aunque siempre con el acuerdo previo del editor.

Los autores deben presentar en una hoja aparte sus datos personales completos: nombre, cargo, dirección, teléfono, fax y correo electrónico.

Los artículos han de presentarse en tres copias impresas, debidamente maquetadas según la plantilla disponible en www.ibersid.org con su gráficos incluidos. Irán precedidos de sus títulos, resúmenes informativos y palabras clave, todos ellos en inglés y español. Además, se deberá enviar por correo electrónico o en un disco compacto una copia en archivo de ordenador en formato Microsoft Word o RTF.

Todos los apartados, incluidos las notas, referencias y apéndices irán numerados secuencialmente. Los subapartados —cuyos títulos serán claros y sintéticos- deberán tener la forma "1.1. ", "1.2. ", "1.2.1. " y así sucesivamente. No numere los resúmenes en español y en inglés, ni los apartados de notas, agradecimien- tos y referencias. Evite un rango de encabezamientos superior a tres.

No se deben relatar datos analíticos repetitivos ni elencos de recursos en el texto principal. Por favor, preséntelos en forma de tablas o, si fuera imposible, en forma de apéndice.

El editor podrá realizar cambios de estilo para adecuar el trabajo a los requisitos de la revista.

Se recuerda al autor que la violación de derechos intelectuales y códigos éticos es un comportamiento inaceptable y puede constituir un grave delito.

\section{Formatos de texto}

No utilice subrayados, negritas ni versales.

Utilice mayúsculas sólo para acrónimos. No ponga puntos y espacios entre las letras que los forman.

Las cursivas se deben utilizar tan sólo para resaltar términos en otras lenguas, títulos de obras, palabras clave muy importantes que podrían servir a modo de títulos de un párrafo o conjunto de párrafos, y, con parquedad, para enfatizar los demás términos y frases a gusto del autor.

No utilice listas con salto de línea o de párrafo. Redacte párrafos completos según las reglas y los recursos gramaticales disponibles en su lengua de redacción. Puede indicar orden en las enumeraciones por medio de números o letras entre paréntesis, como, por ejemplo, $(1 ; 2) \ldots$

\section{Figuras y gráficos}

Las figuras deben presentarse también en ficheros aparte en formato EPS o PDF con resolución de impresión de alta calidad (600 ppp) y, además, en el formato de la aplicación original con la que se creó. Tenga cuidado si genera imágenes a partir de la pantalla de su ordenador. Si recurre a imprimir pantalla en Windows obtendrá solo una resolución de 72 ppp. En ese caso, utilice una pantalla lo más grande posible, amplíe la ventana al máximo, copie con la tecla "impr pant", pegue en el programa "Paint" y guarde el fichero; compruebe luego los resultados. Existen programas que permiten obtener imágenes de pantalla a una resolución acepta- 
ble. En el cuerpo del artículo las imágenes portarán epígrafes indicativos de su contenido precedidos de la palabra "Figura" y un número correlativo (por ejemplo, "Figura 1.").

\section{Tablas}

Deben realizarse con el mismo procesador de textos que el artículo. En texto portarán epígrafes indicativos de su contenido precedidos de la palabra "Tabla" y un numeral romano correlativo (por ejemplo, "Tabla I. ").

\section{Notas}

Las notas explicativas deben usarse excepcionalmente. No utilice el sistema automático de su procesador de textos. Refiéralas en texto tecleando su número secuencial entre paréntesis, e inclúyalas al final del trabajo en un apartado titulado "Notas" situado inmediatamente antes del dedicado a las "Referencias", en orden secuencial y precedida cada una de ellas de su correspondiente número entre paréntesis seguido de tabulador. Las citas bibliográficas se realizarán como en el resto del texto; y la referencia completa se incluirá en el apartado de "Referencias". Las páginas web se consideran referencias bibliográficas y deben tratarse como tales, evitando su cita como nota.

\section{Citas bibliográficas en texto}

Las referencias bibliográficas en texto se denotarán por el apellido del autor, el año del trabajo $y$, si es necesario, el número de página. Si conviene, el nombre y el apellido del autor podrán quedar fuera del paréntesis. Cuando se sucedan seguidamente varias referencias al mismo autor y obra, se podrá usar la abreviatura ibidem. Si dos autores de la lista de referencias poseen el mismo primer apellido, se referirán por sus dos apellidos y, si tienen ambos apellidos iguales, por el nombre también. Si dos o más trabajos del mismo autor son del mismo año, se distinguirán mediante letras del alfabeto secuenciales en minúsculas pospuestas a la fecha sin espacio. Si hay varias referencias dentro del paréntesis, se separarán por punto y coma si son de diferentes autores, y coma si son del mismo.

Así, por ejemplo, "Es una teoría sustentada por varios autores (Gallego, 1975; Fernández y Alonso, 1993) [...]". "Según Jaime Pérez (1993, p. 24) se establecen [...]". "El mismo autor (ibidem, p. 27) hace constar la conveniencia de [...]". "Se han detectado diferencias en la replicación de la experiencia (Menéndez, 1994a, 1994b; Menéndez y Alonso, 1997)".

\section{Formato de las referencias bibliográficas}

Las referencias bibliográficas se incluirán por orden alfabético al final del artículo bajo el título "Referencias". Deberán seguir la norma UNE 50104:1996/ISO 690:1987, y, en cuanto a la puntuación, aproximarse lo más posible a las ISBD abreviadas, aunque sin espacio delante de punto, coma y punto y coma. Las referencias a páginas web deben incluirse también en este apartado, no en el texto ni en nota. Refiera adecuadamente en el texto del articulo toda la bibliografía utilizada; no incluya en el apartado referencias documentos que no haya incluido en el texto. Se presenta a continuación el formato para los principales tipos de materiales, con los elementos que pueden darse o no en cursivas, y seguidos de un ejemplo.

\subsection{Monografías, congresos, informes, normas $\mathrm{y}$ tesis}

Apellido, Nombre; ApellidoN, NombreN (función) (Año). Título: subtítulo. Edición. Lugar de publicación: editor; lugar de publicación: editor, fecha. ISBN número. Tesis doctoral.

Delclaux, Isidoro; Seoane, Julio (1982). Psicología cognitiva y procesamiento de la información: teoría, investigación y aplicaciones. Madrid: Ediciones Pirámide, 1982.

\subsection{Artículos de publicaciones periódicas}

Apellido, Nombre; ApellidoN, NombreN (función) (Año). Título: subtítulo. // Título de la publicación periódica. ISSN numero. Volumen:número (Fecha de publicación) primera página-última página.

Ellis, David (1992a). The physical and cognitive paradigms in Information Retrieval Research. // Journal of Documentation. 48:1 (March 1992) 45-46.

Si coincide la fecha de detrás del autor y la de la localización en la fuente, puede sustituir esta última por una coma.

\subsection{Capítulos de una monografía,} de un informe o contribuciones a un congreso

Apellido, Nombre; ApellidoN, NombreN (función) (Año). Título: subtítulo. // Apellido, Nombre; ApellidoN, NombreN (función) (Año). Título: subtítulo. Edición. Lugar de publicación: editor; lugar de publicación: editor, fecha. ISBN número. Primera página-última página.

Markey, Karen (1990). Keyword searching in an online catalog enhanced with a library classifica- 
tion. // Bengtson, Betty G.; Hill, Janet Swan (eds.). Classification of library materials: current and future potential for providing access. New York: Neal-Shuman Publishers, 1990. 99-125.

Smith, Ph. J.; Beghtol, C.; Fidel, R.; Kwasnik, B. H. (eds.) (1993). Proceedings of the 4th ASIS SIG/CR Classification Research Workshop: Columbus, OH, Oct.24, 1993. Silver Spring, MD.: American Society for Information Science, 1993.

\subsection{Páginas web y recursos en línea}

Se tratarán como monografías, artículos o capítulos según corresponda y se añadirá al final detrás de punto el URL y la fecha de consulta entre paréntesis:

Referencia. URL (Fecha de consulta).

Sagredo Fernández, Félix; Espinosa Temiño, María Blanca (2000). Del libro, al libro electrónico-digital. // Cuadernos de Documentación Multimedia. 9 (2000). http://www.ucm.es/info/multi doc/multidoc/revista/num9/cine/sagredo.htm (2001-01-22).

\section{Apéndice I. El resumen}

Un resumen proporciona información sobre objetivos, alcance, metodología, resultados, conclusiones y recomendaciones. Por alcance se entiende la determinación de hasta qué punto se han tratado los objetivos. Los resultados, conclusiones y recomendaciones se distinguen unos de otros así: los resultados son las informaciones o datos específicos y concretos que se obtienen de la aplicación de la metodología; las conclusiones se derivan de los resultados bien al interpretarlos en el marco de conocimientos teóricos previos o bien al crear un marco de interpretación nuevo a partir de ellos a través de un proceso de abstracción; finalmente, las recomendaciones se refieren a los nuevos problemas y vías de estudio que plantean a la vista de los resultados y conclusiones.

El resumen se debe redactar de forma clara y concisa, sin redundancias ni perífrasis ni información difícil de interpretar, como neologismos o abreviaturas que no se desarrollan.

Es muy conveniente que su primera frase contenga en primer lugar la mención del tipo de documento. Por ejemplo, "Estado de la cuestión sobre la aplicación del modelo europeo de calidad a las bibliotecas universitarias", "Proyecto de aplicación del MARC21 a la catalogación de páginas web institucionales", etc.

\section{Apéndice II. La redacción del artículo científico: algunos aspectos obvios frecuentemente descuidados}

\section{Sistematicidad}

El artículo científico debe redactarse de forma muy organizada, con una estructura textual firme. En los informes de resultados de proyectos, se suele utilizar el esquema objetivosmetodología-resultados- conclusiones- recomendaciones. En los estados de la cuestión se aborda el asunto en orden cronológico o bien sistemático, según la ontología propia del área científica en cuestión; sigue la discusión, la síntesis, las conclusiones y las recomendaciones. Los artículos críticos suelen seguir el esquema tesis-síntesis-antítesis. Otros tipos documentales pueden exigir otras estructuras textuales, pero, en cualquier caso, dicha estructura debe ser explícita y aparente.

Claridad y concisión

El lenguaje del artículo científico debe ser claro y conciso. Excepcionalmente, en los trabajos de tipo ensayístico las personas con un alto dominio del lenguaje escrito pueden permitirse la utilización de recursos literarios.

\section{Pertinencia y parsimonia}

Debe evitarse proporcionar información ya conocida, salvo si constituye el punto central de la discusión. A ella cabe referirse por medio de las citas 0 , si estas no son necesarias, suponerla patrimonio de la comunidad profesional y científica. Sistematizar conocimiento es una función que se realiza solo en un tipo de artículo científico - la revisión o estado de la cuestión-; en los demás casos es contraproducente, aunque se deben citar las fuentes y las obras clave en la introducción del trabajo.

\section{Civilidad}

Es necesario citar a otros autores que han trabajado sobre el tema, demostrando que se conoce la literatura previa y que el trabajo se inserta civilizadamente en un determinado contexto científico. 


\section{Índice de autores}

Author index

Almeida, Carlos Cândido, 145

Bizello, Maria Leandra, 173

Cano de Guadalfajara, Guillermo, 45

Crivelli, Renato, 173

Egea Gilaberte, José Francisco, 45

Escardó i Bas, Mercé, 53

Esteban Sánchez, Ana Lucía, 45

Faba Pérez, Cristina, 101

Galindo Ayuda, Fernando, 111

García Alsina, Montserrat, 77, 135

Gilchrist, Alan, 13

Lasala Calleja, Pilar, 111

López Yepes, José, 89

Madio, Telma Campanha de Carvalho, 179

Manso-Rodríguez, Ramón Alberto, 23
Marcos Recio, Juan Carlos, 65

Múnera Torres, 95

Martins, Rúbia, 145

Millán Reyes, Ana Nieves, 167

Moraes, Cássia Regina Bassan de, 153

Olivera Zaldua, María, 65

Ortoll Espinet, Eva, 77

Pavanelli, Maria Aparecida, 119

Planas i Silva, Carlota, 31

Rico Callado, Francisco Luis, 101

Sánchez Vigil, Juan Miguel, 65

Sebastián Cetina, Daniel, 45

Silva, Luiz Antonio Santana da, 179

Tannuri de Oliveira, Ely Francina, 119

Troitiño, Sonia, 127 


\section{Índice de materias en español}

Subject index in Spanish

Acceso a información, 111

América del Sur, 95

Animación a la lectura, 53

Apple, 31

Aprendizaje, 89

Archivos, 179

Archivos judiciales, 127, 135

Archivos municipales, 45

Bibliotecas, 23, 31

Bibliotecas digitales, 167

Bibliotecas infantiles y juveniles, 53

Bibliotecas públicas, 53

Bibliotecología, 95

Biblioteconomía y Documentación, 101

Cambio digital, 31, 65

Ciencia de la información, 13, 145

Colaboración del lector, 23

Competencias del bibliotecario, 23

Competencias transversales, 101

Comunicación, 65

Concepto, 145

Derecho, 145

Derecho de la competencia, 31

Derechos de autor, 31

Desarrollo, 53

Desarrollo legislativo, 31

Desarrollo tecnológico, 23

Diputación Provincial de Zaragoza, 45

Documentación, 65

Documentación informativa, 65

Documentación jurídica, 135

Documento, 173

Documentos, 145

Documentos audiovisuales, 179

Educación, 53

Enseñanza, 89

Escuela Universitaria Politécnica de La Almunia, 45

Estudiantes universitarios, 89

Estudios de grado, 95, 101

Evaluación, 101

Facebook, 31

Factor humano, 153

Gestión de la información estratégica, 77

Gestión de registros, 135

Gestión del conocimiento., 153

Google, 31
Historia, 13

Historia custodial, 127

Impacto social, 13

Información, 65

Información histórica, 173

Información y Documentación, 89

Innovación, 23

Innovación docente, 111

Innovación tecnológica, 119

Inteligencia competitiva, 77

Interdisciplinariedad, 145

Internet, 111

Juízo de Órfãos de São Paulo, 127

Lectura, 53

Lectura científica, 89

Lefis, 111

Metodología de sistemas suaves, 153

Modelo conceptual, 153

Normalización, 45

Nube, 31

Patentes, 119

Patentometria, 119

Patrimonio cultural, 179

Patrimonio documental, 173

Patrimonio monumental, 173

Perfil de colaboradores, 167

Perfiles profesionales, 95

Prensa, 65

Prensa digital, 65

Privacidad, 31

Proceso lector, 53

Profesionales de la información, 13

Sistema de gestión automatizada de archivos, 45

Sistemas de gestión de documentos, 135

Sistemas documentales, 111

Tecnologías de la información y la comunicación, 13

Tecnologías en bibliotecas, 23

Tercer sector, 167

Transfencia archivística, 127

UNE ISO 30300, 135

Universidad de Extremadura, 101

Universidade Estadual Paulista (Brasil), 119

Voluntariado, 167

Wikipedia, 111

Yahoo, 31 


\title{
Índice de materias en inglés
}

\author{
Subject index in English
}

Access to information, 113

Apple, 31

Archives, 181

Audiovisual documents, 181

Children and juvenile libraries, 53

Cloud, 31

Collaborators' profile, 169

Communication, 67

Competition law, 31

Competitive intelligence, 79

Concept, 147

Conceptual model, 155

Copyright law, 31

Court archives, 129

Court records, 137

Cultural heritage, 181

Cultural proprierty, 175

Custodial history, 129

Development, 53

Digital change, 31, 67

Digital libraries, 169

Digital press, 67

Diputación Provincial de Zaragoza (Spain), 45

Documentation, 67

Documents, 147, 175

Education, 53

Escuela Universitaria Politécnica de La Almunia (Zaragoza, Spain), 45

Evaluation, 103

Facebook, 31

Generic skills, 103

Google, 31

Historical information, 175

Historical records, 175

History, 13

Human factor, 155

Information, 67

Information and communication technologies, 13

Information professionals, 13

Information retrieval systems, 113

Information science, 13, 147

Informative documentation, 67

Interdisciplinarity, 147

Internet, 113
Juízo de Órfãos de São Paulo, 129

Knowledge management, 155

Law, 147

Learning, 91

Lefis, 113

Legislative development, 31

Librarians' competences, 23

Libraries, 23, 31

Library, 97

Library and Information Science, 91, 103

Library technologies, 23

Municipal archives, 45

Patentometrics, 121

Patents, 121

Pregraduate studies, 97, 103

Press, 67

Privacy, 31

Professional profiles, 97

Public libraries, 53

Readers' collaboration, 23

Reading, 53

Reading process, 53

Reading promotion, 53

Records management, 137

Records management systems, 45, 137

Records transfer, 129

Scientific reading, 91

Social impact, 13

Soft system methodology, 155

South America, 97

Strategic information management, 79

Teaching, 91

Teaching innovation, 113

Technological development, 23

Technological innovation, 121

Third sector, 169

UNE ISO 30300, 137

Universidade Estadual Paulista (Brasil), 121

University of Extremadura, 103

University students, 91

Volunteering, 169

Wikipedia, 113

Yahoo, 31 